\title{
Coverage of overdose prevention programs for opiate users and injectors: a cross-sectional study
}

Elisabet Arribas-Ibar ${ }^{1}$, Albert Sánchez-Niubò ${ }^{1}$, Xavier Majó $^{2}$, Antònia Domingo-Salvany ${ }^{1 *}$ and Maria Teresa Brugal ${ }^{3}$

\begin{abstract}
Background: The use of opiates, particularly heroin, remains an important cause of morbidity and mortality. Half of the deaths among heroin consumers are attributed to overdose. In response to this problem, overdose prevention programs (OPPs) were designed. The objective of our study was to assess coverage of OPPs among the target population in a specific Spanish region (Catalonia) and to identify characteristics related to attendance.

Methods: A cross-sectional survey recruited individuals from outpatient treatment centers (OTCs), therapeutic communities (ThCs), and harm reduction facilities (HRFs) in Catalonia. From 513 participants, 306 opiate users and/ or injectors were selected for this study. Coverage was calculated as the proportion of subjects who declared having participated in an OPP. A Poisson regression with robust variance was used to assess factors (socio-demographic aspects and psychoactive substance use patterns) associated to OPP participation, taking into account recruitment strategy.

Results: Average age of the 306 subjects was 39.7 years (s.d.: 7.7); 79\% were male; 79.2\% lived in urban areas and $56.3 \%$ were unemployed or had never worked. Overall OPP coverage was 43.5\% (95\% Cl: 37\%-49\%). Training was received mostly in HRF (60\%), followed by OTC (24.4\%), prison (19\%), and ThC (16\%). OPP sessions were attended by $41 \%$ of Spanish-born study participants and by $63.3 \%$ of foreigners; $92.2 \%$ of the participants lived in urban areas. The Poisson regression analysis adjusted by age, sex, and type of recruitment center showed that OPP participation rates were higher for individuals with foreign nationality ( $\mathrm{PR}=1.3 ; 95 \% \mathrm{Cl}: 1.04-1.72)$, for those living in municipalities with more than 100,000 inhabitants ( $P R=2.0 ; 95 \% \mathrm{Cl}$ : $1.37-2.81$ ) or the Barcelona conurbation ( $\mathrm{PR}=2.5 ; 95 \% \mathrm{Cl}: 1.68-3.77$ ), and for those having ever been in prison ( $\mathrm{PR}=1.6 ; 95 \% \mathrm{Cl}: 1.41-1.81)$ and had first consumption when they were less than 12 years old (PR $=1.2 ; 95 \% \mathrm{Cl}$ : 1.06-1.45).
\end{abstract}

Conclusion: Coverage as a whole can be considered high. However, in Catalonia, new strategies ought to be developed in order to attract opiate users and injectors not currently participating, by expanding OPP offer to services and regions where coverage is poor.

Keywords: Coverage, Drug injectors, Harm reduction program, Heroin overdose, Opiates users, Drug and overdose prevention program

\footnotetext{
* Correspondence: adomingo@imim.es

${ }^{1}$ Research group of drug abuse epidemiology, IMIM—-Institut Hospital del Mar d'Investigacions Mèdiques, Doctor Aiguader 88, E-08003 Barcelona, Spain Full list of author information is available at the end of the article
} 


\begin{abstract}
Antecedentes: El uso de opiáceos, sobre todo heroína, sigue siendo una causa importante de morbilidad y mortalidad. La mitad de las muertes entre consumidores de heroína se atribuyen a sobredosis. Como respuesta a este problema, se desarrollaron los Programas de Prevención de Sobredosis (PPS). El objetivo fue evaluar la cobertura de PPS e identificar las características relacionadas con la asistencia.

Métodos: Estudio transversal de consumidores reclutados en Centros de Tratamiento (CT), Comunidades Terapéuticas (COT) y Centros de Reducción de Daños (CRD) en Cataluña (España). A partir de 513 participantes, se seleccionaron 306 consumidores de opiáceos y/o inyectores. La cobertura fue calculada como la proporción de sujetos que declararon haber participado en un PPS. Se realizó una regresión de Poisson con varianza robusta para evaluar los factores (aspectos socio-demográficos y patrones de consumo de drogas), asociados a la participación en PPS teniendo en cuenta la estrategia de reclutamiento.

Resultados: La edad media fue de 39.7 años (de: 7.7); 79\% eran hombres; 79.2\% vivían en zonas urbanas y 56.3\% eran desempleados o que nunca habían trabajado. En general, la cobertura de PPS fue del 43.5\% (IC 95\%: 37\%-49\%). La mayoría de los programas se realizaron en CRD (60\%), seguido por CT (24.4\%), cárcel (19\%) y CoT (16\%). El 41\% de los participantes nacidos en España participaron en un PPS mientras que lo hicieron un 63.3\% de los extranjeros; el 92.2\% de los participantes vivían en zonas urbanas. Se realizó regresión de Poisson para el análisis, ajustado por edad, sexo y centro de reclutamiento. Se obtuvieron mayores tasas de participación en PPS en personas nacidas en el extranjero (RP $=1.3 ; 95 \%$ IC: 1.04-1.72), residentes en municipios con más de 100.000 $(R P=2.0 ; 95 \%$ IC: 1.37-2.81) y Barcelona conurbación ( $R P=2.5 ; 95 \%$ IC: $1.68-3.77)$, en aquellos que habían estado alguna vez en la cárcel (RP $=1.6 ; 95 \%$ IC: 1.41-1.81) y en los que hicieron el primer consumo con menos de 12 años $(\mathrm{RP}=1.2 ; 95 \% \mathrm{IC}: 1.06-1.45)$.

Conclusión: La cobertura puede ser considerada alta, sin embargo en Cataluña nuevas estrategias deben ser desarrolladas con el fin de atraer consumidores de opiáceos y/o inyectores que no participan, mediante la ampliación de la oferta de PPS en los centros y las regiones donde la cobertura es deficiente.
\end{abstract}

\section{Background}

Currently, substance abuse remains a huge public health problem worldwide, despite different measures having been undertaken in terms of prevention and treatment for legal and illegal drugs [1]. It is estimated that globally, over 27 million people are affected by problematic consumption of some kind of substance (0.6\%). In numerous developed countries, illicit drug use rates are alarming, opiates being one of main substances involved [1-4]. The European Commission and the EU drugs agency (EMCDDA) have estimated that in 2010, there were over 1.3 million active opiate users in Europe [5] and the average prevalence of problematic use is estimated to be between 3.9 and 4.4 individuals per 1,000 persons aged 15-64 years [2]. Furthermore, heroin has been classified as the second most harmful psychoactive drug, taking into account harm to self and others [6], and remains an important cause of morbidity and mortality [2]. Different studies have estimated that around half of the deaths of heroin consumers may be attributed to overdose [7], even though a cohort study in Barcelona found that $34.7 \%$ were due to opiate overdose, probably in relation to the high AIDS-related mortality there [8]. However, it has been estimated that only around $2 \%-3 \%$ of heroin overdoses are fatal [9]. On the other hand, studies have shown that the annual prevalence of non-fatal overdose episodes is $9 \%-32 \%[9,10]$. Even when non-fatal, they can still have serious health consequences $[10,11]$.

Circumstances and consequences of consumption are almost always involved in heroin-related deaths [12]. The risk of heroin overdose, whether fatal or non-fatal, is related to factors such as parenteral route of administration [13] and polydrug use [2,7], especially with central nervous system depressors (e.g. alcohol, benzodiazepines) [10,14,15]. Using heroin when alone and using heroin after a period of abstinence have been established as risk factors for fatal opiate overdose $[12,16]$.

To reduce the health impact that heroin use entails, different strategies have been developed. In several countries, treatment and prevention programs were set up to diminish heroin-associated harm and mortality [7,14]. Among other therapeutic approaches, substitution treatment programs have been highly valuable, with methadone substitution being one of the most widely employed. Methadone maintenance programs have been shown to reduce incidence of both fatal and non-fatal heroin overdoses $[8,17]$. Despite the effectiveness of these programs, a considerable number of heroin addicts, whether or not enrolled in them, continue heroin use and thus remain at an increased risk of suffering from health problems, including 
overdose. Harm reduction programs were created to reduce fatal and non-fatal consequences of heroin use. They include needle exchange programs, safe injection sites, naloxone distribution, and overdose prevention programs (OPPs) [14].

Accidental overdoses usually occur in the company of peers whose immediate help may be critical to assist the overdose victim. Furthermore, as death from overdose usually occurs within $1-3 \mathrm{~h}$ after heroin injection $[14,18]$, there is time to act in order to avoid the opiate poisoning being fatal. This fact led to the development of overdose prevention programs (OPPs), special courses designed $[14,18]$ to teach opiate users how to avoid suffering an overdose and train them in treating those of their peers [19]. The OPP consist of explaining the risks and consequences of opiate use, as well as teaching participants to recognize signs of overdose, how to deal with an overdose step by step, and instruction in cardiopulmonary resuscitation technique and naloxone administration [14,19-21]. Naloxone as an opiate antagonist is very useful to reverse an opiate overdose and as several feasibility studies have demonstrated its effectiveness [22], training in its administration has been incorporated into OPP. Prior studies have shown that drug users trained in OPP are very effective in recognizing overdose signs and in reducing overdose deaths [23].

In Catalonia (Spain), opiate use by injection continues to be prevalent [24]. The region has been identified as having a high mortality rate for opiate overdose [25]. Many treatment and prevention programs started first in Barcelona and subsequently expanded, mainly to other urban areas. Implementation of OPP appears to have followed a similar pattern until their systematic application started, first in centers where harm reduction programs are offered (2009), followed by therapeutic communities (2010) and outpatient treatment centers (2011) [XM, personal communication]. These programs last around $1 \mathrm{~h}$ and participants receive an economic reward. Coverage of these programs needs to be evaluated in order to guarantee their adequacy [23]. In this sense, the main aim of the present study was to assess coverage of OPPs among the target population and to identify characteristics related to attendance.

\section{Methods}

\section{Study design and sample}

The sample for this cross-sectional study was recruited in treatment and prevention centers in Catalonia (Spain) between April and June 2012. A total of 48 centers were selected: 26 outpatient treatment centers (OTCs), 12 therapeutic communities (ThCs), and 10 harm reduction facilities (HRFs). Sampling was planned to cover the whole territory, each center was required to recruit a number of participants determined based on their activity, over-sampling the smallest selected centers, especially HRF. In OTC, this was done only for those having more than 45 annual patients; and in each OTC, a convenience sample was selected, taking into account whether first treatment and time in treatment. Approval for the study was obtained from the IMIM (Hospital del Mar Medical Research Institute) ethics committee, and ethical procedures were followed for data collection. Participants were informed of the purpose of the study, and HRF clients were rewarded with $10 €$.

From a sample of 513 drug users $(N$ approached $=$ 564; participation rate: $91 \%$ ), the target population was selected for the present study, consisting of 312 opiate (i.e. heroin, methadone) users and/or injectors. Participants answered a 78-item questionnaire involving single or multiple-choice answers and different levels of complexity. It was clearly structured and asked for information about socio-demographic aspects, drug patterns, illegal drug market activities, violence, health status, and evaluation of prevention programs. Most questionnaires were administered by a previously trained interviewer; a minority of participants completed the questionnaires themselves. Only four participants did not answer questions about participation in OPPs and two didn't know about participation (1.9\% of the target population). Therefore the final sample consisted on 306 opiate users and/or injectors.

The coverage of OPPs was calculated for the total sample, by recruitment center, region, and municipalities, as the proportion of subjects who declared having participated in an OPP. Variables of interest for OPP participation analysis were recruitment center, sociodemographic aspects (sex, age, country, municipality, level of education, employment status, and sentenced to prison), and psychoactive substance use patterns (age at first drug use, first drug used, parenteral administration, heroin and cocaine use, alcohol risk consumption, and binge drinking). Alcohol risk consumption was assessed through the AUDIT, short version [26]. Other variables of interest were those related to OPPs (type of training center and when they had attended OPP).

\section{Statistical analyses}

Poisson regression models with robust variance were used to analyze association of OPP attendance with the other variables mentioned above via prevalence ratios (PR), adjusted by sex and age [27]. In addition, correlated observations according to the type of recruitment center (HRF, OTC, or ThC) were taken into account through the generalized estimating equation procedure. Analyses consisted in two steps. Firstly, we used distinct 
Poisson regressions (bivariate) for each variable, taking non-attendance in OPP as the reference category. Later, those variables with $p$-value $<0.2$ were included in a multiple Poisson regression. Final model was fitted using a backward procedure. Statistical significance was set at $p$-value $<0.05$. All analyses were performed using PASW Statistics version 18 .

\section{Results}

Among the 306 participants, 68.3\% were opiate users and injectors, $28.4 \%$ were only opiate users, and $3.3 \%$ only injectors. The majority of participants were male (79.2\%). The average age was 39.7 years (s.d.: 7.7) (range: 20-71). Only $24 \%$ had high school or university degree. Over half of the participants had never worked or were unemployed (56.3\%), 26.2\% received a pension or had some permanent disability, and $12 \%$ were currently working; $57.3 \%$ of participants had a prison history. Regarding drug use patterns, alcohol risk consumption was observed in $45.4 \%$ of study participants; $18 \%$ started illegal drug use when they were under 13 years old; and in $76.3 \%$, the first illegal drug used was cannabis.

One hundred thirty-three study participants had participated in some OPPs (43.5\%; 95\% CI: 37\%-49\%). No significant differences were found in the distribution of OPP participation by either sex (men $44.6 \%$ vs women $39 \%$ ) or age (mean age of OPP participants: 39.4 years $\mathrm{s}$. d.: 7.1$) ; 66.7 \%$ of participants recruited in HRF had attended an OPP, while only around one-third of individuals recruited in OTC and ThC had done so (Table 1). OPP coverage by geographical area shows that people living in Barcelona city or Barcelona metropolitan conurbation (BMC) had the highest participation (52.3\%) (Table 1). Related to time of attendance, $63.4 \%$ had attended within the last 2 years, $19.1 \%$ between 2-5 years ago, and $17.6 \%$ more than 5 years ago. Among 131 OPP participants reporting where they had received training, 60\% did so in HRF, $24.4 \%$ in OTC, $19 \%$ in prisons, and $16 \%$ in ThC (note that they could have attended an OPP several times).

Regarding the associations in the bivariate analyses, between OPP participation and other individual variables (Table 2), socio-demographic characteristics found to be significantly associated to OPP attendance were: being a foreigner $(\mathrm{PR}=1.5 ; 95 \% \mathrm{CI}$ : $1.12-2.03)$; municipality, as residents from Barcelona and towns of more than 100,000 habitants had a higher participation; employment status as individuals with permanent disability or receiving a pension were more likely to have attended an OPP and also prison as persons who had ever been sentenced to prison declared a higher participation. Regarding drug use-related variables, we found that participants aged 12 years or under when they first used drugs
Table 1 Overdose prevention program (OPP) coverage by recruitment center and geographical area

\begin{tabular}{|c|c|c|c|c|}
\hline \multirow[b]{3}{*}{ Recruitment center } & \multicolumn{4}{|c|}{ Attendance to OPP } \\
\hline & \multirow{2}{*}{$\begin{array}{c}\boldsymbol{N} \\
306\end{array}$} & \multicolumn{3}{|c|}{ Yes } \\
\hline & & $n$ & $\%$ & $95 \% \mathrm{Cl}$ \\
\hline Outpatient treatment center & 156 & 50 & 32.1 & $(27 \%-37 \%)$ \\
\hline Therapeutic communities & 54 & 19 & 35.2 & $(30 \%-41 \%)$ \\
\hline Harm reduction facilities & 96 & 64 & 66.7 & $(61 \%-72 \%)$ \\
\hline Municipality & 305 & & & \\
\hline Barcelona & 130 & 66 & 50.8 & $(45 \%-56 \%)$ \\
\hline BMC & 49 & 29 & 59.2 & $(54 \%-65 \%)$ \\
\hline More than 100,000 inhabitants $^{a}$ & 63 & 27 & 42.9 & $(37 \%-49 \%)$ \\
\hline 10,001 to 100,000 inhabitants $^{a}$ & 37 & 9 & 24.3 & $(19 \%-29 \%)$ \\
\hline Up to 10,000 inhabitants $^{a}$ & 26 & 2 & 7.7 & $(5 \%-11 \%)$ \\
\hline Provinces & 300 & & & \\
\hline Barcelona and BMC & 176 & 92 & 52.3 & $(47 \%-58 \%)$ \\
\hline Barcelona $^{a}$ & 56 & 19 & 33.9 & $(29 \%-39 \%)$ \\
\hline Tarragona & 28 & 4 & 14.3 & $(10 \%-18 \%)$ \\
\hline Lleida & 20 & 10 & 50 & $(44 \%-56 \%)$ \\
\hline Girona & 20 & 5 & 25 & (20\%-30\%) \\
\hline
\end{tabular}

BMC Barcelona metropolitan conurbation.

${ }^{\mathrm{a}}$ Without Barcelona or BMC.

were more likely to have enrolled in OPP (PR $=1.4 ; 95 \%$ CI: 1.19-1.75).

The multiple Poisson regression analysis showed that being a foreigner was associated to a greater chance of participating ( $\mathrm{PR}=1.3$; 95\% CI: 1.04-1.72), as was residing in a town with more than 100,000 habitants $(\mathrm{PR}=$ 2.0; 95\% CI: $1.37-2.81$ ) or the Barcelona conurbation $(\mathrm{PR}=2.5$; 95\% CI: 1.68-3.77); also, individuals ever sentenced to prison were more likely to have participated in OPP $(\mathrm{PR}=1.6 ; 95 \% \mathrm{CI}: 1.41-1.81)$, as were subjects whose first drug use was when they were 12 years old or under $(\mathrm{PR}=1.2 ; 95 \% \mathrm{CI}: 1.06-1.45)$.

\section{Discussion}

Participation in overdose prevention programs by the target study population was high, $43.5 \%$. Coverage was higher in Barcelona city and its conurbation. Characteristics of participants associated to higher participation in OPP in Catalonia were: residing in metropolitan areas, being a foreigner, having been in prison, and starting consumption at age 12 years or under.

In this study, an attempt was made to achieve maximum representativeness of the target population, selecting participants from all over Catalonia, but as recruitment was only done in health centers, results can at most be representative of drug users in healthcare settings. We need to assume that the interviewed users are similar to their peers. Injectors not reporting opiate use were also 
Table 2 Socio-demographic and psychoactive substance use patterns associated to participation in overdose prevention programs (OPPs)

\begin{tabular}{|c|c|c|c|c|c|c|}
\hline \multicolumn{3}{|c|}{ Attendance to OPP } & \multicolumn{2}{|c|}{$\begin{array}{c}\text { Bivariate poisson } \\
\text { Regression }^{\mathrm{a}}\end{array}$} & \multirow{2}{*}{\multicolumn{2}{|c|}{$\begin{array}{c}\text { Multiple poisson } \\
\text { Regression }^{\mathrm{a}}\end{array}$}} \\
\hline & & & & & & \\
\hline \multirow[t]{2}{*}{$N$} & & & PR & $95 \% \mathrm{Cl}$ & PR & $95 \% \mathrm{Cl}$ \\
\hline & $n$ & $\%$ & & & & \\
\hline
\end{tabular}

Socio-demographic characteristics

Country of origin

Spain

Other countries ${ }^{b}$

306

Municipality

Less than 100,000 inhabitants; not BMC

More than 100,000 inhabitants; not BMC

Barcelona and BMC

Level of education

High school/university degree

Secondary education

Primary/elementary

Employment status

Working

Never worked/unemployed

Permanent disability/pensioner

Student/sporadic work/working at home

Ever sentenced to prison

No

Yes

Psychoactive substance use patterns

Age at first drug use

$\geq 13$ years

$\leq 12$ years

First drug used

Cannabis (marijuana, hashish)

Cocaine, heroin, her-coca, crack

Other drugs ${ }^{c}$

Parenteral administration

No

Yes

Heroin use

No

Yes

Alcohol risk consumption ${ }^{d}$

No

Yes

$C l$ confidence interval, $P R$ prevalence ratio, $B M C$ Barcelona metropolitan conurbation.

${ }^{*} p<0.05$.

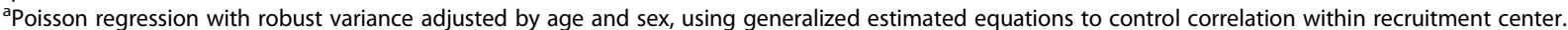

bOther countries: rest of Europe, America, Asia, and North Africa.

'Other drugs: include tranquilizers, mushrooms, LSD, and ketamine.

${ }^{\mathrm{d}}$ According to AUDIT [26]. 
considered target population because intravenous illegal drug use in Catalonia is strongly associated with heroin use [24]. Nevertheless, the resulting sample might be too small to assess coverage precisely or to ascertain the association of some variables. Another limitation would be related to information and recall biases as reporting could be influenced by desirability responses. However, some drug user studies have shown that cross-sectional results are valid despite being self-reported [28].

To our knowledge, no other studies have investigated the coverage of overdose prevention programs in a given geographical area. Coverage of other harm reduction strategies in Spain was ascertained by Barrio et al., concluding that implementation of such strategies arrived late [29]. OPP could not be examined at that point but as, in Catalonia, their systematic implementation did not begin until 2009, we can affirm that they also arrived late. However, in the present study, estimated mean coverage was above $40 \%$, considered high by WHO, UNODC, and UNAIDS Technical Guide for clients of harm reduction programs receiving information, education, and communication [30]. Nevertheless, in this study, we found that some non-systematic provision of such programs took place in our region before 2009. In this respect, we would like to emphasize the importance of systematic implementation of these programs as almost two-thirds (63\%) of the study participants had done so in the years when it was systematic. In 2009, programs were regulated in terms of education materials (e.g. videos) and professional training; however, data from the present study reflects the progressive incorporation of HRF, ThC, and OTC, participation being high only in HRF.

OPP coverage by regions and municipalities was unequal. It was much higher in large cities, not only Barcelona city and conurbation; as other cities with more than 100,000 inhabitants had a coverage of nearly $43 \%$ which could be considered high. In Catalonia, HRF are mainly located in large metropolitan areas. As in other places [31], the higher concentration of drug users in large urban areas prompted the setting up of these preventive interventions there. Starting OPP in HRF may also be considered coherent with the perceived need of OPP there, as such facilities take care of users currently using the drug. Nevertheless, such interventions should also be offered in OTC, ThC, and prisons in order to prevent, and provide the skills to assist, unexpected overdoses when resuming after a period of abstinence [32,33]. The fact that more of our subjects recruited in HRF declared having participated in OPP and that HRF were the facilities where higher OPP attendance was reported by participants is a consistent finding (the type of center where subjects had received the OPP was correlated with recruitment center, data not shown).
OPP is considered an important support tool for overdose prevention policies which aim at reducing or avoiding deaths or health consequences. Previous studies have looked at the effectiveness of OPP, evaluating knowledge, skills learned, and drug prescription among attendants $[22,34,35]$. Different studies indicate that the vast majority of participants are ready to cope with an overdose after having participated in an OPP [36,23]. One study found that $96 \%$ of drug users who were trained to identify overdose risk symptoms and administer naloxone treatment reported positive outcomes, such as avoiding death, coma, and brain damage [37]. Naloxone training is considered a very effective preventive measure within OPPs $[23,19]$. Other studies have found that over half of the participants acquired knowledge and skills sufficient to perform rescue breathing in an overdose situation $[37,38]$. The satisfaction of participants in OPP has been also assessed in some studies, finding them enthusiastic about these training programs [39] and that they feel grateful for and comfortable using the skills and tools acquired [18]. Unfortunately, in our region, there has been no evaluation of how many overdoses may have been prevented after OPP implementation.

In Catalonia, between 2009 and 2011, a total of 2,681 drug users participated in OPPs. It is interesting to note that in this study, people born abroad, with prison antecedents and those who initiated consumption early (aged under 13), reported more participation in OPP. Nearly half of the OPP participants in this study were recruited in HRF, and although recruitment center was controlled for in the regression analysis, participants' characteristics are more similar to clients from HRF. Taking into account that HRF started OPP earlier, they are located in large cities, and most of them are open all day; such results were not unexpected. Some of the services offered in these centers, such as the so-called 'calor-café, tend to attract drug users with social problems or other hardship, by allowing them to remain on the premises for a while, thus favoring their enrollment in preventive programs. This population may include immigrants and people who have been in prison. HRFs may be the first point of contact with healthcare centers and treatment for people born abroad $[40,41]$. They may also be relevant for released prison inmates who learnt about the importance of harm reduction strategies while in prison $[16,33,42]$. As a whole, according to these results, so far OPPs have mainly focused on the needs of the most socially excluded, attracted by HRF, than on those of individuals having more theoretical risk (for example, drug users in OTC).

\section{Conclusions}

Our study allowed assessing OPP coverage in Catalonia, showing that although as a whole the coverage can be 
considered high, less densely populated areas have a medium-poor coverage. Characteristics of OPP attenders paralleled those of HRF users, as subjects recruited there were more prone to have participated. New strategies would need to be developed to attract the target population by offering more OPP in services and regions where participation is poor and assessing why Spaniards have lower involvement in these programs.

\section{Abbreviations}

BMC: Barcelona metropolitan conurbation; Cl: Confidence interval; HRF: Harm reduction facilities; OPP: Overdose prevention programs; OTC: Outpatient treatment centers; PR: Prevalence ratio; ThC: Therapeutic communities; UNAIDS: United Nations and AIDS; UNODC: United Nations Office on Drugs and Crime; WHO: World Health Organization.

\section{Competing interests}

The authors declare that they have no competing interests.

\section{Authors' contributions}

All authors participated in the study design. EAI and ASN conducted the statistical analysis. EAl together with TB and ADS interpreted the results. EAI drafted the first manuscript that was subsequently revised and approved by all authors. All authors read and approved the final manuscript.

\section{Acknowledgements}

Funding for this study was provided by the Spanish Government Grant: Instituto de Salud Carlos III-FIS PI11/01358. Further financial support was provided by the Agència de Gestió d'Ajuts Universitaris i de Recerca (AGAUR 2009 SGR 718) and FIS-Redes de investigación cooperativa RD12/0028/0018. We give our thanks to the participants, the collaborating centers, and their professionals. We are also grateful to Dave Macfarlane for editing and English revision.

\section{Author details}

${ }^{1}$ Research group of drug abuse epidemiology, IMIM-Institut Hospital del Mar d'Investigacions Mèdiques, Doctor Aiguader 88, E-08003 Barcelona, Spain. ${ }^{2}$ Public Health Agency of Catalonia, Edifici Salvany, Roc Boronat 81-95, 08005 Barcelona, Spain. ${ }^{3}$ Public Health Agency of Barcelona, PI. Lesseps 1, 08023 Barcelona, Spain.

Received: 31 October 2013 Accepted: 7 November 2014

Published: 22 November 2014

\section{References}

1. European Monitoring Centre for Drugs and Drug Addiction: Annual Report 2009. The State of the Drug Problem in Europe. Luxembourg: Publications Office of the European Union; 2009.

2. European Monitoring Centre for Drugs and Drug Addiction: Annual report 2012: The state of the drugs problem in Europe. Luxembourg: Publications Office of the European Union; 2012

3. United Nations Office on Drugs and Crime: World drug report 2012. Vienna; 2012

4. United Nations Office on Drugs and Crime: World drug report 2013. Vienna; 2013

5. Strang J, Groshkova T, Metrebian N: Insights. Lisbon: New heroin assistedtreatment. Recent evidence and current practices of supervised injectable heroin treatment in Europe and beyond. European Monitoring Centre for Drugs and Drug Addiction; 2013.

6. Nutt DJ, King LA, Phillips LD: Drug harms in the UK: a multicriteria decision analysis. Lancet 2010, 376:1558-1565.

7. Darke S, Hall W: Heroin overdose: research and evidence-based intervention. J Urban Health 2003, 80:189-200.

8. Brugal MT, Domingo-Salvany A, Puig R, Barrio G, de Garcia OP, de la Fuente $L$ : Evaluating the impact of methadone maintenance programmes on mortality due to overdose and aids in a cohort of heroin users in Spain. Addiction 2005, 100:981-989.

9. Darke S, Ross J, Hall W: Overdose among heroin users in Sydney, Australia: II. Responses to overdose. Addiction 1996, 91:413-417.
10. Brugal MT, Barrio G, De LF, Regidor E, Royuela L, Suelves JM: Factors associated with non-fatal heroin overdose: assessing the effect of frequency and route of heroin administration. Addiction 2002, 97:319-327.

11. Gossop M, Griffiths P, Powis B, Williamson S, Strang J: Frequency of nonfatal heroin overdose: survey of heroin users recruited in non-clinical settings. BMJ 1996, 313:402.

12. Cami J, Domingo-Salvany A: Factores de riesgo en la muerte por heroína. The risk factors in death from heroin. Med Clin (Barc) 1995, 105:455-456.

13. Miller PG: Safe using messages may not be enough to promote behaviour change amongst injecting drug users who are ambivalent or indifferent towards death. Harm Reduct J 2009, 6:18.

14. Sporer KA: Strategies for preventing heroin overdose. BMJ 2003, 326:442-444.

15. Sporer KA: Acute heroin overdose. Ann Intern Med 1999, 130:584-590.

16. Binswanger IA, Blatchford PJ, Mueller SR, Stern MF: Mortality after prison release: opioid overdose and other causes of death, risk factors, and time trends from 1999 to 2009. Ann Intern Med 2013, 159:592-600.

17. Torrens M, Fonseca F, Castillo C, Domingo-Salvany A: Methadone maintenance treatment in Spain: the success of a harm reduction approach. Bull World Health Organ 2013, 91:136-414.

18. Seal KH, Downing M, Kral AH, Singleton-Banks S, Hammond JP, Lorvick J, Ciccarone D, Edlin BR: Attitudes about prescribing take-home naloxone to injection drug users for the management of heroin overdose: a survey of street-recruited injectors in the San Francisco Bay area. J Urban Health 2003, 80:291-301.

19. Neira-Leon M, Barrio G, Bravo MJ, Brugal MT, de la Fuente L, Domingo-Salvany A, Pulido J, Santos S, Project Itinere Group: Infrequent opioid overdose risk reduction behaviours among young adult heroin users in cities with wide coverage of HIV prevention programmes. Int J Drug Policy 2011, 22:16-25.

20. Heller DI, Stancliff S: Providing naloxone to substance users for secondary administration to reduce overdose mortality in New York City. Public Health Rep 2007, 122:393-397.

21. Maxwell S, Bigg D, Stanczykiewicz K, Carlberg-Racich S: Prescribing naloxone to actively injecting heroin users: a program to reduce heroin overdose deaths. J Addict Dis 2006, 25:89-96.

22. Dettmer K, Saunders B, Strang J: Take home naloxone and the prevention of deaths from opiate overdose: two pilot schemes. BMJ 2001, 322:895-896.

23. Wagner KD, Valente TW, Casanova M, Partovi SM, Mendenhall BM, Hundley $J H$, Gonzalez M, Unger JB: Evaluation of an overdose prevention and response training programme for injection drug users in the Skid Row area of Los Angeles, CA. Int J Drug Policy 2010, 21:186-193.

24. Observatorio Español de la Droga y las Toxicomanías: Informe 2011. Situación y tendencias de los problemas de drogas en España. Delegación del Gobierno para el Plan Nacional sobre Drogas. Madrid: Ministerio de Sanidad y Política Social; 2011.

25. Bargagli AM, Hickman M, Davoli M, Perucci CA, Schifano P, Buster M, Brugal T, Vicente J, COSMO European Group: Drug-related mortality and its impact on adult mortality in eight European countries. Eur $J$ Public Health 2006, 16:198-202.

26. Contel M, Gual A, Colom J: Test para la identificacion de trastornos por uso de alcohol (AUDIT): traduccion y validacion del AUDIT al catalan y castellano. Addicciones 1999, 11:337-347.

27. Coutinho LM, Scazufca M, Menezes PR: Methods for estimating prevalence ratios in cross-sectional studies. Rev Saude Publica 2008, 42:992-998.

28. Maisto SA, McKay JR, Connors GJ: Self-report issues in substance abuse: state of the art and future directions. Behav Assess 1990, 12:117-134.

29. Barrio G, Bravo MJ, Brugal MT, Diez M, Regidor E, Belza MJ, de la Fuente L, Itinere Working Group: Harm reduction interventions for drug injectors or heroin users in Spain: expanding coverage as the storm abates. Addiction 2012, 107:1111-1122.

30. World Health Organization, United Nations Office on Drugs and Crime, United Nations AIDS: Technical Guide for countries to set targets for universal access to HIV prevention, treatment and care for injecting drug users. Geneva; 2009.

31. World Health Organization: Effectiveness of sterile needle and syringe programming in reducing HIV/AIDS among injecting drug users. Geneva; 2004.

32. Davoli M, Bargagli AM, Perucci CA, Schifano P, Belleudi V, Hickman M, Salamina G, Diecidue R, Vigna-Taglianti F, Faggiano F, VEdeTTE Study Group: Risk of fatal overdose during and after specialist drug treatment: the VEdeTTE study, a national multi-site prospective cohort study. Addiction 2007, 102:1954-1959. 
33. Hakansson A, Berglund M: All-cause mortality in criminal justice clients with substance use problems-a prospective follow-up study. Drug Alcohol Depend 2013, 132:499-504.

34. Green TC, Heimer R, Grau LE: Distinguishing signs of opioid overdose and indication for naloxone: an evaluation of six overdose training and naloxone distribution programs in the United States. Addiction 2008, 103:979-989.

35. Piper TM, Rudenstine S, Stancliff S, Sherman S, Nandi V, Clear A, Galea S: Overdose prevention for injection drug users: lessons learned from naloxone training and distribution programs in New York City. Harm Reduct J 2007, 4:3.

36. Frisher M, Baldacchino A, Crome I, Bloor R: Preventing Opioid Overdoses in Europe: A Critical Assessment of Known Risk Factors and Preventative Measures. EMCDDA, Lisbon: European Monitoring Centre for Drugs and Drug Addiction Technical paper; 2012.

37. Bennett AS, Bell A, Tomedi L, Hulsey EG, Kral AH: Characteristics of an overdose prevention, response, and naloxone distribution program in Pittsburgh and Allegheny County, Pennsylvania. J Urban Health 2011, 88:1020-1030

38. Enteen L, Bauer J, McLean R, Wheeler E, Huriaux E, Kral AH, Bamberger JD: Overdose prevention and naloxone prescription for opioid users in San Francisco. J Urban Health 2010, 87:931-941.

39. Marchand Kl, Oviedo-Joekes E, Guh D, Brissette S, Marsh DC, Schechter MT: Client satisfaction among participants in a randomized trial comparing oral methadone and injectable diacetylmorphine for long-term opioid-dependency. BMC Health Serv Res 2011, 11:174.

40. Anton Jl, de Munoz BR: Health care utilisation and immigration in Spain. Eur J Health Econ 2010, 11:487-498.

41. Saigi N, Espelt A, Folch C, Sarasa-Renedo A, Castellano Y, Majo X, Meroño M, Brugal MT, Casabona J, REDAN Group: Differences in illegal drug consumption between native and immigrants in a large sample of injected drug users in Catalonia (Spain). Adicciones 2014, 26:69-76.

42. Huang YF, Kuo HS, Lew-Ting CY, Tian F, Yang CH, Tsai TI, Gange SJ, Nelson KE: Mortality among a cohort of drug users after their release from prison: an evaluation of the effectiveness of a harm reduction program in Taiwan. Addiction 2011, 106:1437-1445.

Cite this article as: Arribas-lbar et al:: Coverage of overdose prevention programs for opiate users and injectors: a cross-sectional study. Harm Reduction Journal 2014 11:33.

\section{Submit your next manuscript to BioMed Central and take full advantage of:}

- Convenient online submission

- Thorough peer review

- No space constraints or color figure charges

- Immediate publication on acceptance

- Inclusion in PubMed, CAS, Scopus and Google Scholar

- Research which is freely available for redistribution 